\title{
Chemical manipulation of glucose metabolism in porcine oocytes: effects on nuclear and cytoplasmic maturation in vitro
}

\author{
Jason R Herrick, Amber M Brad and Rebecca L Krisher \\ Department of Animal Sciences, Program of Comparative Medicine, Lilly Hall of Life Sciences, \\ 915 West State Street, Purdue University, West Lafayette, Indiana 47907, USA
}

Correspondence should be addressed to R L Krisher; Email: rkrisher@purdue.edu

\begin{abstract}
The objectives of this study were to manipulate metabolism of glucose through glycolysis and the pentose phosphate pathway (PPP) in porcine oocytes during in vitro maturation, and determine the effects of this manipulation on meiotic progression, intracellular glutathione (GSX) concentrations and embryonic development. Cumulus-oocyte complexes isolated from abattoir ovaries were matured (40-44 h) in Purdue Porcine Medium for maturation alone (control) or supplemented with pyrroline-5 carboxylate (PC, $0.1 \mu \mathrm{M}$; PPP stimulator), diphenyleneiodonium (DPI, $0.1 \mu \mathrm{M}$; PPP inhibitor), dinitrophenol (DNP, $10 \mu \mathrm{M}$; glycolytic stimulator), hexametaphosphate (HMP, $100 \mu \mathrm{M}$; glycolytic inhibitor), PC + HMP or DNP + DPI. At the conclusion of in vitro maturation, cumulus cells were removed and oocytes were randomly allocated for analysis of GSX, metabolism and nuclear maturation, or in vitro fertilization and embryo culture. Both DPI and DNP + DPI decreased $(P \leq 0.05)$ the activity of glycolysis and the PPP, increased $(P \leq 0.05)$ the percentage of immature oocytes, and decreased $(P \leq 0.05)$ the proportion of mature oocytes compared with control oocytes and oocytes from the other treatments. Embryonic development (cleavage and blastocyst stage) and the intracellular content of GSX were also decreased $(P \leq 0.05)$ following exposure to DPI or DNP + DPI compared with control oocytes and oocytes from the other treatments. Oocyte metabolism, nuclear maturation, GSX content and embryonic development were unaffected $(P>0.05)$ following exposure to PC, DNP, HMP or PC + HMP. Our results suggest that metabolism of glucose through the PPP and/or glycolysis plays a key role in the control of nuclear and cytoplasmic maturation of porcine oocytes in vitro.

Reproduction (2006) 131 289-298
\end{abstract}

\section{Introduction}

Oocyte maturation encompasses a variety of cellular changes necessary for normal fertilization and successful embryonic development. These changes can be roughly categorized as nuclear or cytoplasmic maturation (Eppig 1996). Nuclear maturation refers to the progression of the chromatin through meiosis from the germinal vesicle (GV) stage to arrest at the second metaphase (MII). In contrast, cytoplasmic maturation includes all of the other changes within the oocyte, such as accumulation of mRNA and protein, reorganization of the cytoskeleton and organelles, and changes in cellular metabolism. Although nuclear and cytoplasmic maturation are often discussed separately, the numerous processes involved are interrelated and critical for successful embryonic development.

Similarly to other cells, oocytes metabolize glucose via glycolysis, the pentose phosphate pathway (PPP), and the tricarboxylic acid cycle (mice, Downs \& Utecht 1999; cats, Spindler et al. 2000; cattle, Rieger \& Loskutoff 1994,
Krisher \& Bavister 1999; sheep, O’Brien et al. 1996; pigs, Durkin et al. 2001). Resumption of meiosis is associated with elevated activity of glycolysis and the PPP, as well as increased activity of hexokinase (glycolsis and PPP), phosphofructokinase (glycolysis), and glucose-6 phosphate dehydrogenase (PPP) within the cytoplasm of the oocyte (Tsutsumi et al. 1992, Downs et al. 1996, Downs \& Utecht 1999, Cetica et al. 2002). In mice, gonadotropininduced meiosis is dependent on the presence of glucose (Fagbohun \& Downs 1992, Downs \& Mastropolo 1994). Increased metabolism of glucose through one or more metabolic pathways also occurs simultaneously with the progression of meiosis to MII in oocytes from cats (Spindler et al. 2000) and cattle (Rieger \& Loskutoff 1994, Steeves \& Gardner 1999). In primate oocytes, glucose is necessary for cytoplasmic maturation, although nuclear maturation can occur in the absence of carbohydrates (Zheng et al. 2001). In addition, elevated glucose metabolism in mature oocytes is correlated with, and predictive of, improved embryonic development in cats and cattle (Krisher \& Bavister 1999, 
Spindler et al. 2000, Spindler \& Wildt 2002). Similarly, oocytes matured in vitro from cats and pigs metabolize significantly less glucose and have lower developmental potential than oocytes matured in vivo (Spindler et al. 2000, Durkin et al. 2001). These findings highlight the importance of glucose metabolism in oocyte maturation and the interactions between nuclear and cytoplasmic maturation.

Another important aspect of oocyte maturation is the accumulation of glutathione (GSX). This tripepetide (GluCys-Gly) is involved in many aspects of oocyte physiology including cumulus cell expansion, sperm decondensation, male pronuclear formation and embryonic development (cattle, de Matos et al. 1995, Sutovsky \& Schatten 1997, Furnus et al. 1998; sheep, de Matos et al. 2002; pigs, Yoshida 1993, Yoshida et al. 1993; hamsters, Zuelke et al. 2003). Both steps in the synthesis of GSX, addition of glutamate and cysteine and the addition of glycine to this dipepetide, are dependent on ATP, and therefore dependent on the metabolism of the oocyte (Stryer 1995). Once synthesized, GSX cycles between the reduced (GSH) and oxidized (GSSG) form through the actions of GSX reductase and GSX peroxidase. The peroxidase transfers electrons from GSH to oxidized molecules within the cytoplasm, minimizing the actions of various oxidative stressors and resulting in the production of GSSG (Guérin et al. 2001). The cellular pool of GSH is maintained by reduction of GSSG to GSH by GSX reductase, as well as further GSH synthesis. The reduction of GSSG requires NADPH, a product of the PPP. Therefore, intracellular concentrations of GSH, and the many processes affected by GSH, are tightly linked to the metabolic activity of the oocyte.

Glucose metabolism and GSX accumulation are important for successful oocyte maturation and embryonic development in pigs (Abeydeera et al. 2000, Durkin et al. 2001, Brad et al. 2003a,b, Herrick et al. 2003a). However, the interactions between nuclear maturation, glucose metabolism, GSX concentrations and embryonic development are unclear. The objective of this study was to elucidate these mechanisms in porcine oocytes. Chemical agents were used to alter the activity of glycolysis and/or the PPP during in vitro maturation of porcine oocytes, and then nuclear maturation, oocyte metabolism, GSX concentrations and embryonic development were evaluated. We hypothesized that increased glucose metabolism would lead to improved nuclear (MII) and cytoplasmic (intracellular GSX and developmental potential) maturation.

\section{Materials and Methods}

\section{Chemicals and media preparation}

Unless specified otherwise, all chemicals were purchased from Sigma Chemical Co. (St Louis, MO, USA). All media contained $100 \mathrm{U} / \mathrm{ml}$ penicillin, $100 \mu \mathrm{g} / \mathrm{ml}$ streptomycin, and $0.25 \mathrm{ng} / \mathrm{ml}$ amphotericin (GibcoBRL Products,
Gaithersburg, MD, USA). Maturation, fertilization, and culture media were freshly prepared from stock solutions for each replicate, filtered $(0.22 \mu \mathrm{m}$, Millex GV; Millipore Corp., Bedford, MA, USA) immediately before use, and equilibrated at $38.7^{\circ} \mathrm{C}$ in the appropriate gas atmosphere.

\section{Oocyte recovery and in vitro maturation}

Ovaries from pre-pubertal gilts were collected at a local abattoir and transported to the laboratory in $0.9 \%(\mathrm{w} / \mathrm{v})$ $\mathrm{NaCl}\left(30-34^{\circ} \mathrm{C}\right)$. Ovaries were washed with fresh saline and $3-8 \mathrm{~mm}$ follicles were aspirated with an 18 gauge needle attached to a vacuum pump. Oocytes surrounded by a minimum of two layers of cumulus cells with a uniform cytoplasm were selected and washed twice in Hepes-buffered synthetic oviductal fluid (SOF-Hepes) containing $0.3 \%(\mathrm{w} / \mathrm{v})$ BSA, $1.0 \mathrm{mM}$ glutamine, and both essential $(1 \times)$ and nonessential $(1 \times)$ amino acids (ICN Biomedicals, Costa Mesa, CA, USA). Cumulus-oocyte complexes (COCs) were then washed and cultured $(5 \%$ $\mathrm{CO}_{2}$ in air) for $40-44 \mathrm{~h}$ in $500 \mu \mathrm{l}$ maturation medium under $500 \mu \mathrm{l}$ mineral oil in a four-well plate (50-60 COCs/ well; Nunclon, Nalge Nunc Intl, Rochester, NY, USA). Maturation medium was Purdue Porcine Medium (PPM) modified for oocyte maturation (PPM Mat; Stroble et al. 2002, Herrick et al. 2003b), containing $0.6 \mathrm{mM}$ cysteine, $0.5 \mathrm{mg} / \mathrm{ml}$ hyaluronate (MAP5; Vetrepham Inc., Athens, GA, USA), $10 \mathrm{ng} / \mathrm{ml}$ epidermal growth factor, $0.01 \mathrm{U} / \mathrm{ml}$ porcine luteinizing hormone and follicle-stimulating hormone (FSH) (Sioux Biochemical, Sioux Center, IA, USA), and $1 \times$ MEM vitamins (ICN Biomedicals). After oocytes were placed into maturation medium (PPM Mat), no further selection was performed throughout the experiment.

\section{In vitro fertilization}

At the conclusion of maturation, cumulus cells were removed by agitating COCs in $100 \mu$ l SOF-Hepes with $0.01 \%(\mathrm{w} / \mathrm{v} ; 80-160 \mathrm{U} / \mathrm{ml})$ hyaluronidase for $2-3 \mathrm{~min}$ using a vortex mixer. Cumulus-free oocytes were then washed twice in SOF-Hepes, and randomly allocated for fertilization, metabolism or GSX analysis. For fertilization, oocytes were washed twice in PPM fertilization medium (PPM Fert.2) containing $44 \mathrm{mM}$ bicarbonate, $0.2 \%(\mathrm{w} / \mathrm{v})$ fatty-acid free BSA, and $2.0 \mathrm{mM}$ caffeine (Herrick et al. $2003 \mathrm{~b}$ ) and placed into $50 \mu \mathrm{l}$ drops of PPM Fert.2 under $4 \mathrm{ml}$ mineral oil (20 oocytes/drop; Falcon 1008; Becton Dickinson Labware, Franklin Lakes, NJ, USA).

Frozen, ejaculated sperm was thawed in $2.0 \mathrm{ml}$ of $\mathrm{Ca}^{2+}$-free phosphate-buffered saline (PBS, Gibco), and processed through a $45 \%: 90 \%$ gradient of Percoll by centrifugation for $20 \mathrm{~min}$ at $1000 \mathrm{~g}$. The resulting sperm pellet was washed in $5.0 \mathrm{ml}$ PBS containing $0.1 \%(\mathrm{w} / \mathrm{v})$ Fraction $\mathrm{V}$ BSA by centrifuging for $5 \mathrm{~min}$ at $1000 \mathrm{~g}$. Sperm were diluted $\left(1 \times 10^{6}\right.$ sperm $\left./ \mathrm{ml}\right)$ in fertilization medium (PPM Fert.2), and added $(50 \mu \mathrm{l})$ to fertilization drops containing oocytes for a final sperm concentration of 
$5 \times 10^{5}$ sperm $/ \mathrm{ml}$. Gametes were coincubated for $5 \mathrm{~h}$ in $5 \% \mathrm{CO}_{2}$ in air.

\section{Embryo culture}

Following coincubation, zygotes were washed three times in PPM culture medium 1 (PPM1) with $0.4 \%(\mathrm{w} / \mathrm{v})$ crystallized BSA (Serologicals Proteins, Inc., Kankakee, IL, USA) to remove loosely bound sperm, and cultured in $50 \mu \mathrm{l}$ drops PPM1 (ten zygotes/drop; Falcon 1007) under $10 \mathrm{ml}$ mineral oil in $5 \% \mathrm{CO}_{2}, 10 \% \mathrm{O}_{2}, 85 \% \mathrm{~N}_{2}$ (Durkin et al. 2002, Stroble et al. 2002, Herrick et al. 2003b). After 3 days of culture, embryos were washed three times in PPM2 (0.4\% crystallized BSA) and placed into $50 \mu \mathrm{l}$ drops of PPM2 for an additional 3 days of culture $\left(5 \% \mathrm{CO}_{2}\right.$, $10 \% \mathrm{O}_{2}, 85 \% \mathrm{~N}_{2}$ ). The number of embryos that cleaved was determined at the time of moving into PPM culture medium 1 (PPM2). On day 6 of culture, the proportion of oocytes that developed to the blastocyst stage was determined and all blastocysts were fixed and stained to determine total cell number. Briefly, blastocysts were counterstained with $0.1 \%(\mathrm{w} / \mathrm{v})$ trypan blue in $2.3 \%(\mathrm{w} / \mathrm{v})$ citrate for $1 \mathrm{~min}$ and then stained with $0.01 \mathrm{mg} / \mathrm{ml}$ Hoechst 33342 for 5 min (Pursel et al. 1985). Cells were counted under fluorescent illumination at $\times 400$.

\section{Assessment of glucose metabolism and nuclear maturation}

Following maturation and cumulus-cell removal, oocytes were washed twice in a simple, PPM-based metabolism medium containing $1.2 \mathrm{mM}$ unlabelled glucose, $1.5 \mathrm{mM}$ lactate, $0.1 \mathrm{mM}$ pyruvate, and $0.5 \mathrm{mg} / \mathrm{ml}$ hyaluronate. Glycolysis and PPP were simultaneously measured using [5- ${ }^{3} \mathrm{H}$ ]glucose $(0.021 \mathrm{mM}, 0.25 \mu \mathrm{Ci} / \mu \mathrm{l}$; Perkin-Elmer NEN Life Sciences Inc., Boston, MA, USA) and $\left[1-{ }^{14} \mathrm{C}\right]$ glucose $(0.482 \mathrm{mM}, \quad 0.0265 \mu \mathrm{Ci} / \mu \mathrm{l}$; American Radiolabeled Chemicals Inc., St Louis, MO, USA) respectively (O'Fallon \& Wright 1986, Rieger \& Guay 1988, Krisher \& Bavister 1999). Radiolabeled glucose was dissolved in metabolism medium and equilibrated at $38.7^{\circ} \mathrm{C}$ in $5 \% \mathrm{CO}_{2}$ in air. Oocytes were collected in $2 \mu \mathrm{l}$ metabolism medium, combined with $2 \mu \mathrm{l}$ medium containing radiolabeled glucose, and placed in the cap of a $1.5 \mathrm{ml}$ microcentrifuge tube in a single, $4 \mu \mathrm{l}$ drop. The cap containing the oocyte was then replaced onto a $1.5 \mathrm{ml}$ microcentrifuge tube filled with $1.5 \mathrm{ml} 25 \mathrm{mM} \mathrm{NaHCO}$ and the remaining air space gassed with $5 \% \mathrm{CO}_{2}$ in air as the lid was secured. Drops not containing an oocyte (blanks) were included in each assay to monitor nonspecific release of ${ }^{14} \mathrm{C}$ and ${ }^{3} \mathrm{H}$. In addition, the total amount of radioactivity per tube was determined in each assay by thoroughly mixing metabolism drops without oocytes with the $\mathrm{NaHCO}_{3}$ trap. After a $3 \mathrm{~h}$ incubation $\left(38.7^{\circ} \mathrm{C}\right)$, the caps were removed, $1 \mathrm{ml} \mathrm{NaHCO}_{3}$ trap was added to a scintillation vial containing $200 \mu \mathrm{l} 0.1 \mathrm{M} \mathrm{NaOH}$, and the vials stored for $24 \mathrm{~h}$ at $4^{\circ} \mathrm{C}$. Ten milliliters of scintillation fluid (Ecolite; ICN) were added to each vial, vials were shaken briefly, and then held at $25^{\circ} \mathrm{C}$ for at least $24 \mathrm{~h}$ before measuring radioactivity on a liquid scintillation counter. When counts for one or both of the pathways were less than the mean value of the blanks, the oocyte was considered nonviable and not included in the analysis. Oocytes were recovered from the caps and fixed (6:3:1, ethanol:acetic acid:chloroform) for a minimum of $24 \mathrm{~h}$. Chromatin was then stained with $1 \%(\mathrm{w} / \mathrm{v})$ orcein in $45 \%(\mathrm{v} / \mathrm{v})$ acetic acid and observed with differential interference contrast microscopy $(x 400)$ to evaluate nuclear maturation. Oocytes were classified as containing a GV, undergoing GV breakdown (GVBD), containing condensed chromatin (CC), or having reached metaphase I $(\mathrm{MI})$, anaphase I (AI), telophase I (TI) or MII. Oocytes arrested at GV, GVBD or CC were considered immature (Motlik \& Fulka 1976, Funahashi et al. 1997), while oocytes reaching $\mathrm{Al}, \mathrm{TI}$ or MII were considered mature.

\section{Determination of intracellular GSX concentrations}

Groups of cumulus-free oocytes were washed three times in $0.4 \mathrm{M} \mathrm{NaPO}_{4}$ buffer containing $10 \mathrm{mM}$ EDTA, taken up in $5 \mu \mathrm{l}$ of this buffer, transferred to $1.5 \mathrm{ml}$ microcentrifuge tubes, and stored at $-80^{\circ} \mathrm{C}$. Aliquots $(5 \mu \mathrm{l})$ of the buffer were also frozen in each replicate to serve as blanks. GSX assays utilizing the dithiobisnitrobenzoic acid (DTNB)GSSG reductase recycling reaction were performed as described by Baker et al. (1990) and modified for use with embryos by Aréchiga et al. (1995). Briefly, $45 \mu l$ water were added to each tube and the entire contents transferred to a well of a 96 well microtiter plate. GSX standards $(50 \mu \mathrm{l}$ water containing $0.4-200 \mathrm{pmol}$ GSH) were also added to individual wells. DTNB (1 mM), NADPH $(1 \mathrm{mM})$ and GSX reductase $(200 \mathrm{U} / \mathrm{ml})$ were dissolved in assay buffer (200 $\mathrm{mM} \mathrm{NaPO}_{4}, 1 \mathrm{mM}$ EDTA, pH 7.5) and combined $(5 \mathrm{ml}$ DTNB, $5 \mathrm{ml} \mathrm{NADPH}, 5.75 \mathrm{ml}$ assay buffer, and $0.1 \mathrm{ml}$ or $20 \mathrm{U}$ GSSG reductase). One hundred microliters of this reaction mixture were added to each well, and the plate immediately loaded into a microtiter plate reader. Formation of thionitrobenzoic acid was monitored by measuring absorbance at $410 \mathrm{~nm}$ at $30 \mathrm{~s}$ intervals (0-6 min of incubation). The rate of change of absorbance per minute was determined for each well and concentrations of GSX in the samples (pmol/oocyte) were computed from a standard curve (rate of change of absorbance vs pmol GSX/well) and the number of oocytes in each well. Medium blanks in this assay were equivalent to $0.55 \pm 0.12 \mathrm{pmol}$ GSX/well or $0.055 \pm 0.012 \mathrm{pmol}$ GSX/oocyte. Since these effects accounted for only a small portion of the measured GSX values and were not different $(P>0.05)$ between treatments, sample values were not corrected to compensate for blank effects. Due to the presence of NADPH and GSSG reductase, this assay measures both GSSG and GSH concentrations and all values are reported as pmol GSX/oocyte. 


\section{Chemicals for metabolic manipulation}

A variety of chemicals were tested to find a stimulator and inhibitor of glycolysis and the PPP. The electron acceptors methylene blue $(1000,100,10,1,0.1,0.01 \mu \mathrm{M})$, phenazine ethosulfate $(10,1,0.1,0.01,0.001 \mu \mathrm{M})$, and pyrroline-5 carboxylate (PC; 250, 100, 10, 1, $0.1 \mu \mathrm{M}$ ) were tested as potential PPP stimulators. Diphenyleneiodonium (DPI; 100, 10, 1, 0.1, 0.01, $0.001 \mu \mathrm{M}$ ), an inhibitor of NADPH oxidase, and 6-aminonicotinamide $(25,10,1$, $0.1,0.01 \mu \mathrm{M})$ an inhibitor of glucose 6-phosphate dehydrogenase and 6-phosphogluconate dehydrogenase, were tested as possible PPP inhibitors. Sodium azide $(10 \mu \mathrm{M})$ and 2,4-dinitrophenol (DNP; $10 \mu \mathrm{M})$, an inhibitor and uncoupler of oxidative phosphorylation respectively were evaluated as possible glycolytic stimulators. Hexametaphosphate (HMP; 5, 1, 0.5, 0.1, $0.01 \mathrm{mM}$ (Zollner 1999)) and EDTA $(10 \mu \mathrm{M})$ were tested as glycolytic inhibitors.

Initially, COCs were exposed to four doses (ten COCs/ dose) of each chemical, except sodium azide, DNP and EDTA, during maturation. A second replicate was then performed with an additional four doses (ten COCs/dose) of each chemical that overlapped the most promising doses from the first replicate. Sodium azide, DNP and EDTA were tested (two replicates of ten COCs/chemical/ replicate) at concentrations used previously in murine (Lane \& Gardner 2001) or bovine (Thompson et al. 2000, Rieger et al. 2002) embryos. At the conclusion of maturation, cumulus cells were removed and the metabolic activity of each oocyte was assessed. Oocyte metabolism was evaluated instead of COC metabolism because it is the metabolism of the oocyte, not the COC or cumulus cells, that has been correlated with developmental competence (O'Brien et al. 1996, Krisher \& Bavister 1999, Spindler et al. 2000, Spindler \& Wildt 2002). The concentration of each chemical that had the most profound and consistent effect on metabolism was selected (data not shown). Stock solutions of each chemical were prepared in culture grade $(18.2 \mathrm{M} \Omega$ ) water, and 1-20 $\mu \mathrm{l}$ were added to $2 \mathrm{ml}$ PPM Mat prior to equilibration and addition of COC. Final concentrations used and intended effects of each chemical are shown in Table 1.

Table 1 Dose and intended effect of chemicals used to alter metabolism of glucose through the pentose phosphate pathway and glycolysis in porcine oocytes.

\begin{tabular}{lcl}
\hline Treatment & Dose & Intended effect \\
\hline Control & $\mathrm{NA}$ & None \\
PC & $0.1 \mu \mathrm{M}$ & $\uparrow \mathrm{PPP}$ \\
$\mathrm{DPI}$ & $0.1 \mu \mathrm{M}$ & $\downarrow$ PPP \\
DNP & $10 \mu \mathrm{M}$ & $\uparrow$ Glycolysis \\
$\mathrm{HMP}$ & $100 \mu \mathrm{M}$ & $\downarrow$ Glycolysis \\
$\mathrm{HMP}+\mathrm{PC}$ & $100 \mu \mathrm{M} / 0.1 \mu \mathrm{M}$ & $\downarrow$ Glycolysis/ $\uparrow \mathrm{PPP}$ \\
$\mathrm{DNP}+\mathrm{DPI}$ & $10 \mu \mathrm{M} / 0.1 \mu \mathrm{M}$ & $\uparrow$ Glycolysis/ $\downarrow$ PPP \\
\hline
\end{tabular}

Reproduction (2006) 131 289-298

\section{Statistical analysis}

Due to the limited number of oocytes available on a single day (approximately 150), three experimental groups (treatments or control) were randomly selected to be tested each day. In each replicate (day = replicate), 50 COCs were assigned to each of the three selected groups. At the conclusion of maturation, 20 oocytes were fertilized and cultured, 10 oocytes were assessed for metabolic activity and nuclear maturation, and 20 oocytes (two groups of 10) were used for GSX determination in each replicate. All experimental groups were replicated six or seven (control only) times.

All data were analyzed using ANOVA in the PROC MIXED procedure of SAS. For continuous data (metabolism and GSX), treatment was considered a fixed factor and replicate effect and the treatment by replicate interaction were treated as random factors. The largest and smallest variances among the treatments were used to calculate an F-value, which was used to determine if variance was homogeneous (nonsignificant F-test, $P>0.20$ ) across treatments (Hoshmand 1994). Variances for both metabolic pathways and GSX concentrations were found to be heterogeneous, so a separate variance for each treatment was used for analysis. For binomial data (nuclear maturation, cleavage and blastocyst development) each oocyte or embryo was assigned a 1 if it had achieved the desired stage of maturation or development or a 0 if it had not. These data were analyzed using the generalized linear mixed model (GLIMMIX) macro with treatment as a fixed factor, and replicate and the treatment by replicate interaction as random factors in the initial model (Littell et al. 1996). The error was designated as having a binomial distribution and the probit link function was used. Counts of blastocyst cell numbers were also analyzed with the GLIMMIX macro with treatment as the only factor in the model statement. The error was designated as having a Poisson distribution and the log link function was used. In some cases these models required simplification in order for all parameters to be estimated. Random effects were removed from the model individually, beginning with the treatment by replicate interaction, until all factors could be estimated. For blastocyst development, data for the DNP + DPI treatment were excluded from analysis by the SAS program in order to achieve convergence for the GLIMMIX model. When the ANOVA was significant, Fisher's least significant difference test was used for the comparison of individual treatments. The PROC REG procedure was used to assess correlation between oocyte maturation, embryonic development (dependent variables, transformed by arcsine of the square root of the proportion), or GSX (dependent variable) and metabolism or GSX content (independent variable) within treatments using data paired by replicate ( $n=6$ or 7 ). $P$ values $\leq 0.05$ were considered significant. Means are presented \pm S.E.M. 


\section{Results}

Both DPI and DNP + DPI decreased ( $P \leq 0.05$; Table 2) the activity of glycolysis (DPI, $0.73 \mathrm{pmol} / 3 \mathrm{~h}$ per oocyte and $\mathrm{DNP}+\mathrm{DPI}, 0.58 \mathrm{pmol} / 3 \mathrm{~h}$ per oocyte) and the PPP (DPI, $0.34 \mathrm{pmol} / 3 \mathrm{~h}$ per oocyte and DNP + DPI, $0.31 \mathrm{pmol} / 3 \mathrm{~h}$ per oocyte) relative to control oocytes (glycolysis, $1.56 \mathrm{pmol} / 3 \mathrm{~h}$ per oocyte and PPP, $0.57 \mathrm{pmol} / 3 \mathrm{~h}$ per oocyte; Table 2). The other treatments (PC, DNP, HMP, HMP + PC) failed to significantly $(P>0.05)$ alter the activity of glycolysis or the PPP in the oocytes relative to control oocytes and metabolic rates were not different $(P>0.05)$ between these treatments. Exposure to DPI alone or in combination with DNP increased $(P \leq 0.05)$ the percentage of immature (GV, GVBD or CC) oocytes $(71.9-79.9 \%)$ and decreased $(P \leq 0.05)$ the proportion of mature (Al to MII) oocytes $(7.2-11.1 \%)$ compared with control oocytes $(11.9 \%$ immature and $74.6 \%$ mature; Table 3) and oocytes from the other treatment groups. Maturation after exposure to the other chemicals (2.8$11.0 \%$ immature, $63.5-73.3 \%$ mature) was not different $(P>0.05)$ between treatments or from maturation of control oocytes.

Embryonic development was also inhibited ( $P \leq 0.05)$ by DPI, with or without DNP, compared with control oocytes and oocytes from the other treatments (Table 4). Development was not different $(P>0.05)$ between control oocytes and oocytes treated with PC, DNP, HMP or HMP + PC. A high proportion (75.7-82.3\%) of the oocytes from the other treatment groups, as well as the control, cleaved compared with $5.8-10.0 \%$ of oocytes exposed to DPI (Table 4). Similarly, development to the blastocyst stage was low $(0.0-0.8 \%)$ among oocytes treated with DPI or DNP + DPI, compared with the other treatment groups and control oocytes (7.1-15.1\%, Table 4). Blastocyst cell numbers were similar among all treatments and controls (27.3-38.3 cells/blastocyst, Table 4).

The intracellular content of GSX was not affected $(P>0.05)$ by exposure to $\mathrm{PC}, \mathrm{DNP}, \mathrm{HMP}$ or $\mathrm{PC}+\mathrm{HMP}$ (7.42-8.68 pmol/oocyte) compared with controls (7.37 pmol/oocyte, Table 5). Exposure to DPI decreased $(P \leq 0.05)$ intracellular GSX $(5.35 \mathrm{pmol} /$ oocyte) relative to control oocytes and oocytes from the other treatments, and addition of DNP further decreased ( $P \leq 0.05)$ GSX concentrations (3.37 pmol/oocyte, Table 5).

Among control oocytes and oocytes treated with DNP + DPI, there was a positive correlation between the proportion of mature oocytes and glycolysis $(P \leq 0.05$, $r^{2}=0.71-0.81$; Table 6). Similarly, there were negative correlations $\left(P \leq 0.05, r^{2}=0.70-0.84\right)$ between the proportion of immature oocytes and the activity of glycolysis or the PPP among oocytes treated with DPI, DNP or DNP + DPI (Table 6). In contrast, the proportion of immature oocytes after exposure to PC was positively correlated $\left(P=0.03, r^{2}=0.74\right)$ with glycolytic activity (Table 6$)$. The proportion of mature oocytes was positively correlated $\left(P=0.04, r^{2}=0.69\right)$ with intracellular GSX content among DNP + DPI-treated oocytes (Table 6), and there were positive correlations between GSX content and the glycolytic $\left(P=0.05, \quad r^{2}=0.65\right)$ and PPP $(P=0.02$, $\left.r^{2}=0.78\right)$ activity of DPI-treated oocytes. Embryonic cleavage $\left(P=0.01, r^{2}=0.81\right)$ and GSX content $(P=0.01$, $\left.r^{2}=0.84\right)$ were also positively correlated with glycolytic activity after exposure to DNP + DPI (Table 6). Finally, embryonic cleavage was positively correlated with GSX content $\left(P=0.04, r^{2}=0.69\right)$ after treatment with DNP + DPI. There were no significant correlations $(P>0.05)$ between oocyte metabolism or GSX content and development to the blastocyst stage in any treatment group.

\section{Discussion}

The objective of this study was to manipulate the activity of glycolysis and the PPP in order to determine the interactions between nuclear maturation, cytoplasmic maturation (metabolism and GSX content), and embryonic development in porcine oocytes. Exposing oocytes to DPI, either alone or in combination with DNP, during maturation significantly inhibited glycolysis and activity of the PPP. In addition, DPI-exposed oocytes contained less GSX and fewer of these oocytes matured, cleaved, or developed to the blastocyst stage. These results provide the first evidence of a functional link between glucose metabolism and nuclear maturation in porcine oocytes. Similarly, decreased GSX content following inhibition of glucose metabolism demonstrates for the first time in any species

Table 2 Effects of chemical exposure on the activity (pmol/oocyte per $3 \mathrm{~h}$ ) of glycolysis and pentose phosphate pathway in porcine oocytes.

\begin{tabular}{lcc}
\hline Treatment $(n)^{1}$ & Glycolysis $($ pmol/oocyte per 3 $\mathrm{h})$ & Pentose phosphate pathway (pmol/oocyte per 3 $\mathrm{h}$ ) \\
\hline Control (55) & $1.56 \pm 0.12^{\mathrm{a}}$ & $0.57 \pm 0.06^{\mathrm{c}}$ \\
PC (57) & $1.99 \pm 0.14^{\mathrm{a}}$ & $0.69 \pm 0.04^{\mathrm{c}}$ \\
DPI (39) & $0.73 \pm 0.09^{\mathrm{b}}$ & $0.34 \pm 0.03^{\mathrm{d}}$ \\
DNP (55) & $1.93 \pm 0.14^{\mathrm{a}}$ & $0.67 \pm 0.05^{\mathrm{c}}$ \\
HMP (49) & $1.58 \pm 0.12^{\mathrm{a}}$ & $0.59 \pm 0.06^{\mathrm{c}}$ \\
HMP + PC (49) & $1.61 \pm 0.12^{\mathrm{a}}$ & $0.65 \pm 0.05^{\mathrm{c}}$ \\
DNP + DPI (43) & $0.58 \pm 0.06^{\mathrm{b}}$ & $0.31 \pm 0.04^{\mathrm{d}}$ \\
\hline
\end{tabular}

\footnotetext{
${ }^{1}$ Total number of oocytes evaluated.

$a, b, c, d$ Treatments (mean \pm S.E.M.) within the same column with different superscripts differ $(P \leq 0.05)$.
} 
Table 3 Summary of nuclear maturation in porcine oocytes following chemical exposure during in vitro maturation.

\begin{tabular}{|c|c|c|c|c|c|c|c|c|}
\hline Treatment & $\mathbf{G V}^{1}$ & GVBD/CC ${ }^{2}$ & $\mathrm{MI}^{3}$ & $\mathrm{~A} / \mathrm{TI}^{4}$ & MII $^{5}$ & Total $^{6}$ & Immature $^{7}(\%)$ & Mature $^{8}(\%)$ \\
\hline Control & 0 & 7 & 7 & 3 & 35 & 52 & $11.9 \pm 6.5^{\mathrm{a}}$ & $74.6 \pm 8.0^{c}$ \\
\hline PC & 0 & 1 & 12 & 0 & 32 & 45 & $2.8 \pm 2.8^{\mathrm{a}}$ & $67.8 \pm 10.8^{c}$ \\
\hline DPI & 4 & 31 & 9 & 0 & 4 & 48 & $71.9 \pm 7.9^{\mathrm{b}}$ & $7.2 \pm 3.7^{d}$ \\
\hline DNP & 0 & 4 & 12 & 0 & 35 & 51 & $8.3 \pm 5.3^{\mathrm{a}}$ & $68.3 \pm 8.6^{\mathrm{c}}$ \\
\hline HMP & 0 & 6 & 9 & 1 & 40 & 56 & $11.0 \pm 3.9^{\mathrm{a}}$ & $73.3 \pm 4.7^{\mathrm{c}}$ \\
\hline $\mathrm{HMP}+\mathrm{PC}$ & 1 & 2 & 14 & 1 & 29 & 47 & $6.0 \pm 2.7^{a}$ & $63.5 \pm 6.7^{c}$ \\
\hline $\mathrm{DNP}+\mathrm{DPI}$ & 2 & 31 & 4 & 0 & 6 & 43 & $79.9 \pm 12.4^{\mathrm{b}}$ & $11.1 \pm 11.1^{\mathrm{d}}$ \\
\hline
\end{tabular}

${ }^{1}$ Germinal vesicle.

${ }^{2}$ Germinal vesicle breakdown or condensed chromatin.

${ }^{3}$ Metaphase I.

${ }^{4}$ Anaphase or telophase I.

${ }^{5}$ Metaphase II.

${ }^{6}$ Total number of oocytes assessed for nuclear maturation.

${ }^{7}$ Mean \pm S.E.M. of the percentages of GV, GVBD or CC oocytes in 6 or 7 replicates.

${ }^{8}$ Mean \pm S.E.M. of the percentages of $\mathrm{Al}$, TI or MII oocytes in 6 or 7 replicates.

$\mathrm{a}, \mathrm{b}, \mathrm{c}, \mathrm{d}$ Treatments within the same column with different superscripts differ $(P \leq 0.05)$. Binomial data was analysed using the GLIMMIX macro in PROC MIXED of SAS.

that these two critical aspects of oocyte maturation are interrelated.

The effects of DPI on PPP activity are attributed to its ability to inhibit NADPH oxidase, the enzyme that produces the NADP necessary for PPP activity (Stryer 1995, Downs et al. 1998), but the possibility of toxic effects must be considered due to the severity of the effects of DPI exposure. However, meiotic arrest due to DPI is almost completely reversible in mouse oocytes, with approximately $84 \%$ of DPI-exposed oocytes resuming meiosis (Downs et al. 1998). In addition, the effects of $0.1 \mu \mathrm{M} \mathrm{DPI}$ appear to be reversible in porcine oocytes. At the conclusion of maturation $(40 \mathrm{~h})$ in the presence of DPI $(0.1 \mu \mathrm{M})$, approximately $75 \%$ of oocytes were still at the GV or GVBD stage of meiosis, as seen in the present study (Krisher 2005). After an additional $40 \mathrm{~h}$ of culture in the absence of DPI, only $9.0 \%$ of oocytes remained at the GV or GVBD stages (Krisher 2005). Although only a small percentage of exposed oocytes $(10.1 \%)$ reached MII, the increased proportion of oocytes at MI indicates that $>60 \%$ of DPI-exposed $(0.1 \mu \mathrm{M}, 40 \mathrm{~h})$ porcine oocytes were still viable and capable of resuming meiosis (Krisher 2005).
The likelihood that the effects of DPI are specific to altered glucose metabolism is also supported by the fact that maturation of porcine oocytes in the absence of glucose, but with pyruvate and lactate, results in no embryonic cleavage, similar to what we found in the presence of DPI (Tubman et al. 2005). Therefore, we conclude that the effects of DPI can be attributed to altered glucose metabolism, and the severity of these effects is probably due to the importance of glucose metabolism in porcine oocyte maturation rather than its toxicity.

Treatment with DPI had the intended effect of inhibiting PPP activity, but glycolysis was also decreased. This finding suggests that the mechanisms controlling the PPP and glycolysis are related in porcine oocytes. It may be that increased activity of the PPP is one of the initial stimuli for the resumption of meiosis, while increased glycolysis is a result of the progression of meiosis. In mice, ribose 5-phosphate produced by the PPP is converted to phosphoribosyl pyrophosphate (PRPP), which participates in purine production, via de novo synthesis or the salvage of hypoxanthine, and resumption of meiosis (Downs 1993, 1997). In addition, stimulation of the PPP with either

Table 4 The effects of chemical exposure during in vitro maturation of porcine oocytes on in vitro embryonic development following in vitro fertilization.

\begin{tabular}{lccc}
\hline Treatment $(n)^{1}$ & Cleavage on day $\mathbf{3}(\%)$ & Blastocyst on day $\mathbf{6}(\%$ of oocytes) & ${\text { Blastocyst cel\# }(n)^{2}}^{2}$ \\
\hline Control (140) & $77.1 \pm 4.1^{\mathrm{a}}$ & $7.1 \pm 3.1^{\mathrm{c}}$ & $30.9 \pm 3.8^{\mathrm{e}}(9)$ \\
PC (119) & $78.1 \pm 5.1^{\mathrm{a}}$ & $13.4 \pm 3.6^{\mathrm{c}}$ & $32.9 \pm 4.2^{\mathrm{e}}(8)$ \\
DPI (119) & $10.0 \pm 6.5^{\mathrm{b}}$ & $0.8 \pm 0.8^{\mathrm{d}}$ & $\mathrm{NA}$ \\
DNP (119) & $82.3 \pm 1.8^{\mathrm{a}}$ & $15.1 \pm 4.6^{\mathrm{c}}$ & $38.3 \pm 4.0^{\mathrm{e}}(18)$ \\
HMP (120) & $77.5 \pm 6.7^{\mathrm{a}}$ & $13.3 \pm 3.1^{\mathrm{c}}$ & $28.8 \pm 2.9^{\mathrm{e}}(8)$ \\
HMP + PC (119) & $75.7 \pm 5.5^{\mathrm{a}}$ & $14.3 \pm 3.3^{\mathrm{c}}$ & $27.3 \pm 3.5^{\mathrm{e}}(13)$ \\
DNP + DPI (120) & $5.8 \pm 5.8^{\mathrm{b}}$ & $0.0 \pm 0.0^{*}$ & $N A$ \\
\hline
\end{tabular}

${ }^{1}$ Total number of oocytes cultured in 6 or 7 (control only) replicates.

${ }^{2}$ Number of blastocysts analyzed for cell number.

$\mathrm{a}, \mathrm{b}, \mathrm{c}, \mathrm{d}, \mathrm{e}$ Treatments within the same column with different superscripts differ $(P \leq 0.05)$. Binomial data was analysed using the GLIMMIX macro in PROC MIXED of SAS.

* Excluded from statistical analysis due to lack of blastocysts. 
Table 5 Intracellular GSX content (pmol/oocyte) of porcine oocytes following chemical exposure during in vitro maturation.

\begin{tabular}{lc}
\hline Treatment $(n)^{1}$ & GSX (pmol/oocyte) \\
\hline Control (7) & $7.37 \pm 0.71^{\mathrm{a}}$ \\
PC (6) & $7.42 \pm 0.78^{\mathrm{a}}$ \\
DPI (6) & $5.35 \pm 0.58^{\mathrm{b}}$ \\
DNP (6) & $7.90 \pm 0.85^{\mathrm{a}}$ \\
HMP (6) & $8.18 \pm 0.37^{\mathrm{a}}$ \\
HMP + PC (6) & $8.68 \pm 0.36^{\mathrm{a}}$ \\
DNP + DPI (6) & $3.37 \pm 0.55^{\mathrm{c}}$ \\
\hline
\end{tabular}

${ }^{1}$ Number of replicates. Two pools of 10 oocytes were analysed in each replicate (6 or 7 replicates per treatment).

$a, b, c$ Treatments (mean \pm S.E.M.) within the same column with different superscripts differ $(P \leq 0.05)$.

chemical agents (PC or phenazine ethosulfate) or $\mathrm{FSH}$ induces a significant increase in GVBD in murine oocytes (Downs et al. 1998). Glycolysis has been associated with the maintenance of meiotic arrest in mouse oocytes, but also increases coincidently with maturation in mice, cattle and cats (Downs \& Mastropolo 1994, Downs \& Utecht 1999, Steeves \& Gardner 1999, Spindler et al. 2000). In this study, we found that the glycolytic activity of oocytes was positively correlated with the proportion of mature oocytes in control and DNP + DPI-treated oocytes. In addition, increased activity of the PPP and glycolysis was associated with a decrease in the proportion of immature oocytes after DPI, DNP or DNP + DPI exposure. These results suggest that activity of both the PPP and glycolysis are higher in mature porcine oocytes. It is possible that inhibition of the PPP in porcine oocytes by DPI, prevented nuclear maturation and the associated increase in glycolytic activity. However, whether low metabolism is a cause or a consequence of inhibited maturation remains to be determined. In a follow-up experiment to the present study, the inhibitory effects of DPI $(50 \mathrm{nM})$ on the maturation of porcine oocytes could be overcome by supplementing DPI-containing media with PRPP, ribose 5-phosphate or NADP (Krisher 2005). These findings further support our hypothesis that the PPP is a controlling factor in porcine oocyte maturation, and provide experimental conditions that could be used to determine how DPI affects glycolysis independently of PPP activity and nuclear maturation.

Exposure to DPI during maturation also decreased intracellular GSX concentrations compared with control oocytes and oocytes exposed to the other treatments. In addition, an increased concentration of GSX was associated with a higher proportion of mature oocytes in the presence of DNP + DPI and with increased activity of glycolysis and the PPP in the presence of DPI-exposed oocytes. The concentration of GSX within the oocyte increases throughout maturation in porcine (Yoshida et al. 1993), bovine (Miyamura et al. 1995) and hamster oocytes (Perreault et al. 1988, Zuelke et al. 2003), but it is not known whether this increase is caused by meiotic progression or the associated changes in cellular metabolism. Perhaps the low rates of glycolysis, and presumed decrease in ATP production, in the presence of DPI reduced the synthesis of GSX. Since tricarboxylic acid cycle activity is known to be low in porcine oocytes (Durkin et al. 2001, Sturmey \& Leese 2003), glycolysis may be the primary source of ATP. This hypothesis is supported by the fact that addition of DNP, which disrupts the mitochondrial $\mathrm{H}^{+}$ gradients and inhibits mitochondrial ATP production (Stryer 1995), to DPI further decreased GSX concentrations relative to the DPI group. In contrast, DNP alone did not affect GSX content, possibly due to sufficient ATP production from glycolysis in the absence of DPI. Alternatively, meiosis is associated with changes in RNA transcription and translation of various proteins (Paynton \& Bachvarova 1994, Wu et al. 1996, Dalbiès-Tran \& Mermillod 2003). By inhibiting maturation, DPI may have disrupted these processes and altered the synthesis of GSX independently of changes in metabolic activity or substrate (amino acid and/or ATP) availability. Finally, decreased PPP activity may have altered the REDOX potential of the cytoplasm

Table 6 Linear correlations ${ }^{1}$ between nuclear and cytoplasmic maturation in procine oocytes.

\begin{tabular}{|c|c|c|c|c|c|}
\hline Treatment & Dependent variable ${ }^{2}$ & Independent variable ${ }^{3}$ & Direction & $P$-value & $r^{2}$ \\
\hline Control & $\%$ Mature & Glycolysis & + & 0.02 & 0.71 \\
\hline PC & $\%$ Immature & Glycolysis & + & 0.03 & 0.74 \\
\hline \multirow[t]{3}{*}{ DPI } & $\%$ Immature & PPP & - & 0.04 & 0.70 \\
\hline & GSX & Glycolysis & + & 0.05 & 0.65 \\
\hline & GSX & PPP & + & 0.02 & 0.78 \\
\hline DNP & $\%$ Immature & Glycolysis & - & 0.01 & 0.84 \\
\hline HMP & $\%$ Cleavage & Glycolysis & + & 0.02 & 0.79 \\
\hline \multirow{6}{*}{$\mathrm{DNP}+\mathrm{DPI}$} & $\%$ Immature & Glycolysis & - & 0.02 & 0.76 \\
\hline & $\%$ Mature & Glycolysis & + & 0.01 & 0.81 \\
\hline & $\%$ Mature & GSX & + & 0.04 & 0.69 \\
\hline & GSX & Glycolysis & + & 0.01 & 0.84 \\
\hline & $\%$ Cleavage & Glycolysis & + & 0.01 & 0.81 \\
\hline & $\%$ Cleavage & GSX & + & 0.04 & 0.69 \\
\hline
\end{tabular}

\footnotetext{
${ }^{1}$ Data paired by replicate $(n=6$ or 7$)$.

${ }^{2}$ Percentages were transformed using arcsine of the square root of the proportion.

${ }^{3}$ Rates of glycolysis and PPP activity are pmol/oocyte per $3 \mathrm{~h}$ and GSX values are pmol GSX/oocyte.
} 
(NADPH:NADP and/or GSH:GGSG), interfering with REDOX-regulated processes (Harvey et al. 2002) that could be involved in meiotic resumption, metabolic control, and/or GSX synthesis.

Treatment with DPI, alone or in combination with DNP, also inhibited embryonic cleavage and development to the blastocyst stage. However, the inhibition of cleavage and blastocyst development was most probably associated with the low rate of nuclear maturation induced by DPI. The similarity between the proportion of mature oocytes $(7.2-11.1 \%)$ and the proportion of oocytes that cleaved $(5.8-10.0 \%)$ supports this hypothesis.

In contrast to preliminary observations made in our laboratory (data not shown), PC, DNP and HMP were not effective in significantly altering glucose metabolism in porcine oocytes. Due to the relatively small sample sizes in the dose-response experiments it is possible that the concentrations of chemical agents used were simply insufficient to produce significant effects. However, the lack of significant effects of PC, DNP and HMP on metabolism also may be related to variability in oocyte quality that affects the response to the chemicals. The use of abattoirderived oocytes introduces significant variability within and between replicates due to differences in the histories of the females. In addition, oocytes from pre-pubertal animals are known to have reduced developmental potential (Pinkert et al. 1989, Peters et al. 2001). This variability between oocytes is evident within the metabolic data from control oocytes, where rates (pmol/oocyte per $3 \mathrm{~h}$ ) of glycolysis ranged from 0.02 to 3.46 and those of the PPP ranged from 0.07 to 1.75 . It seems likely that the effects of the chemicals, and the effective dose of each chemical, may be dependent on the initial quality of the oocyte. Metabolic stimulators may fail to have an effect on oocytes with high metabolic activity or poor quality oocytes containing insufficient amounts of metabolic enzymes or substrate transport proteins to support higher levels of metabolism. Similarly, increased concentrations of inhibitors may be necessary to affect high quality oocytes with elevated metabolic activity, while low concentrations of inhibitors might be effective in poor quality oocytes with already depressed metabolic activity. Although COC morphology influences developmental potential (Blondin \& Sirard 1995, Wood \& Wildt 1997, Chauhan et al. 1998), dramatic differences in both metabolism and developmental potential exist among oocytes from morphologically identical COCs matured under identical conditions (Spindler \& Wildt 2002). Development of better methods for selection of a homogeneous group of COCs may be more useful in future studies of this type, rather than prolonged dose-response experiments aimed at identification of a single effective dose. Despite the potential impact of oocyte quality on the metabolic response to chemical exposure, both PC and DNP elicited numeric, nonsignificant increases in mean PPP and glycolytic activity respectively, as predicted. This fact argues against the possibility of an insufficient dose, and supports our hypothesis of an interaction between oocyte quality and chemical response.

Our objective was to alter glucose metabolism using various chemical agents in order to determine how glucose metabolism affects porcine oocyte maturation. Inhibition of glycolysis and the PPP by DPI, alone or in combination with DNP, resulted in more immature oocytes, fewer mature oocytes, lower intracellular concentrations of GSX, and decreased embryonic development. In addition, significant, linear correlations between maturation, metabolism and GSX demonstrated interactions between these cellular functions. Use of alternative chemicals and culture conditions to manipulate metabolism or supplementation of culture media with substrates of reactions downstream of the point of inhibition will be useful in further elucidating the mechanisms of these actions. In conclusion, this study provides the first evidence for a role of glucose metabolism in the control of both nuclear and cytoplasmic maturation of porcine oocytes.

\section{Acknowledgements}

We are grateful to Indiana Packers Co. for donation of ovarian tissue and M Sparman, A Clifford and K Stroble for tissue transport. In addition, Dr T Stewart and Dr N St-Pierre are thanked for discussions concerning statistical analysis. This research was funded by grant \#00-02143 from the United States Department of Agriculture's NRI Competitive Grants Program to R L K. The authors declare that there is no conflict of interest that would prejudice the impartiality of this scientific work.

\section{References}

Abeydeera LR, Wang WH, Cantley TC, Rieke A, Murphy CN, Prather RS \& Day BN 2000 Development and viability of pig oocytes matured in a protein-free medium containing epidermal growth factor. Theriogenology 54 787-797.

Aréchiga CF, Ealy AD \& Hansen PJ 1995 Evidence that glutathione is involved in thermotolerance of preimplantation murine embryos. Biology of Reproduction 52 1296-1301.

Baker MA, Cerniglia GJ \& Zaman A 1990 Microtiter plate assay for the measurement of glutathione and glutathione disulfide in large numbers of biological samples. Analytical Biochemistry $\mathbf{1 9 0}$ $360-365$.

Blondin P \& Sirard M-A 1995 Oocyte and follicular morphology as determining characteristics for developmental competence in bovine oocytes. Molecular Reproduction and Development $4 \mathbf{1}$ $54-62$.

Brad AM, Bormann CL, Swain JE, Durkin RE, Johnson AE, Clifford AL \& Krisher RL 2003a Glutathione and adenosine triphosphate content of in vivo and in vitro matured porcine oocytes. Molecular Reproduction and Development 64 492-498.

Brad AM, Herrick JR, Lane M, Gardner DK \& Krisher RL 2003b Glucose and lactate concentrations affect the metabolism of in vitro matured porcine oocytes. Biology of Reproduction 68 (Supplement 1) 259 (abstract\#356).

Cetica P, Pintos L, Dalvit G \& Beconi M 2002 Activity of key enzymes involved in glucose and triglyceride catabolism during bovine oocyte maturation in vitro. Reproduction 124 675-681.

Chauhan MS, Singla SK, Palta P, Manik RS \& Madan ML 1998 In vitro maturation and fertilization, and subsequent development of buffalo (Bubalus bubalis) embryos: effects of oocyte quality and 
type of serum. Reproduction, Fertility, and Development $\mathbf{1 0}$ $173-177$.

Dalbiès-Tran R \& Mermillod P 2003 Use of heterologous complementary DNA array screening to analyze bovine oocyte transcriptome and its evolution during in vitro maturation. Biology of Reproduction $68252-261$.

de Matos DG, Furnus CC, Moses DF \& Baldassarre H 1995 Effect of cysteamine on glutathione level and developmental capacity of bovine oocyte matured in vitro. Molecular Reproduction and Development 42 432-436.

de Matos DG, Gasparrini B, Pasqualini SR \& Thompson JG 2002 Effect of glutathione synthesis stimulation during in vitro maturation of ovine oocytes on embryo development and intracellular peroxide content. Theriogenology 57 1443-1451.

Downs SM 1993 Purine control of mouse oocyte maturation: evidence that nonmetabolized hypoxanthine maintains meiotic arrest. Molecular Reproduction and Development 35 82-94.

Downs SM 1997 Involvement of purine nucleotide synthetic pathways in gonadotropin-induced meiotic maturation in mouse cumulus cell-enclosed oocytes. Molecular Reproduction and Development 46 155-167.

Downs SM \& Mastropolo AM 1994 The participation of energy substrates in the control of meiotic maturation in murine oocytes. Developmental Biology 162 154-168.

Downs SM \& Utecht AM 1999 Metabolism of radiolabeled glucose by mouse oocytes and oocyte-cumulus cell complexes. Biology of Reproduction 60 1446-1452.

Downs SM, Humpherson PG, Martin KL \& Leese HJ 1996 Glucose utilization during gonadotropin-induced meiotic maturation in cumulus cell-enclosed mouse oocytes. Molecular Reproduction and Development 44 121-131.

Downs SM, Humpherson PG \& Leese HJ 1998 Meiotic induction in cumulus cell-enclosed mouse oocytes: involvement of the pentose phosphate pathway. Biology of Reproduction 58 1084-1094.

Durkin RE, Swain JE, Bormann CL, Frederick AM \& Krisher RL 2001 Metabolism of porcine oocytes matured in vivo and in vitro. Biology of Reproduction 64 (Supplement 1) 138 (abstract\#81).

Durkin RE, Swain JE, Clifford AL \& Krisher RL 2002 Development of a sequential medium for in vitro culture of porcine embryos. Theriogenology 57517 (abstract).

Eppig JJ 1996 Coordination of nuclear and cytoplasmic oocyte maturation in eutherian mammals. Reproduction, Fertility, and Development 8 485-489.

Fagbohun CF \& Downs SM 1992 Requirement for glucose in ligandstimulated meiotic maturation of cumulus cell-enclosed mouse oocytes. Journal of Reproduction and Fertility 96 681-697.

Funahashi H, Cantley TC \& Day BN 1997 Synchronization of meiosis in porcine oocytes by exposure to dibutyryl cyclic adenosine monophosphate improves developmental competence following in vitro fertilization. Biology of Reproduction 57 49-53.

Furnus CC, de Matos DG \& Moses DF 1998 Cumulus expansion during in vitro maturation of bovine oocytes: relationship with intracellular glutathione level and its role on subsequent embryo development. Molecular Reproduction and Development 51 76-83.

Guérin P, El Mouatassim S \& Ménézo Y 2001 Oxidative stress and protection against reactive oxygen species in the pre-implantation embryo and its surroundings. Human Reproduction Update 7 175-189.

Harvey AJ, Kind KL \& Thompson JG 2002 REDOX regulation of early embryo development. Reproduction 123 479-486.

Herrick JR, Brad AM, Krisher RL \& Pope WF 2003a Intracellular adenosine triphosphate and glutathione concentrations in oocytes from first estrous, multi-estrous, and testosterone-treated gilts. Animal Reproduction Science $\mathbf{7 8} 123-131$.

Herrick JR, Conover-Sparman ML \& Krisher RL 2003b Reduced polyspermic fertilization of porcine oocytes utilizing elevated bicarbonate and reduced calcium concentrations in a single medium system. Reproduction, Fertility, and Development $\mathbf{1 5}$ 249-254.
Hoshmand AR 1994 In Experimental Research Design and Analysis. Boca Raton, FL: CRC Press.

Krisher RL 2005 Inhibition of the pentose phosphate pathway results in meiotic arrest in porcine oocytes that can be overcome by the addition of pathway cofactors and end products. Reproduction, Fertility, and Development 17293 (abstract \#287).

Krisher RL \& Bavister BD 1999 Enhanced glycolysis after maturation of bovine oocytes in vitro is associated with increased developmental competence. Molecular Reproduction and Development 53 19-26.

Lane M \& Gardner DK 2001 Inhibiting 3-phosphoglycerate kinase by EDTA stimulates the development of the cleavage stage mouse embryo. Molecular Reproduction and Development 60 233-240.

Littell RC, Milliken GA, Stroup WW \& Wolfinger RD 1996 In SAS System for Mixed Models. Cary, NC: SAS Institute Inc.

Miyamura M, Yoshida M, Hamano S \& Kuwayama M 1995 Glutathione concentration during maturation and fertilization in bovine oocytes. Theriogenology 43282 (abstract).

Motlik J \& Fulka J 1976 Breakdown of the germinal vesicle in pig oocytes in vivo and in vitro. Journal of Experimental Zoology 198 $155-162$.

O'Brien JK, Dwarte D, Ryan JP, Maxwell WMC \& Evans G 1996 Developmental capacity, energy metabolism and ultrastructure of mature oocytes from prepubertal and adult sheep. Reproduction, Fertility, and Development 8 1029-1037.

O'Fallon JV \& Wright RW Jr 1986 Quantitative determination of the pentose phosphate pathway in preimplantation mouse embryos. Biology of Reproduction 34 58-64.

Paynton BV \& Bachvarova R 1994 Polyadenylation and deadenylation of maternal mRNAs during oocyte growth and maturation in the mouse. Molecular Reproduction and Development 37 $172-180$.

Perreault SD, Barbee RR \& Slott VL 1988 Importance of glutathione in the acquisition and maintenance of sperm nuclear decondensing activity in maturing hamster oocytes. Developmental Biology $125181-186$

Peters JK, Milliken G \& Davis DL 2001 Development of porcine embryos in vitro: effects of culture medium and donor age. Journal of Animal Science 79 1578-1583.

Pinkert CA, Kooyman DL, Baumgartner A \& Keisler DH 1989 In vitro development of zygotes from superovulated prepubertal and mature gilts. Journal of Reproduction and Fertility 87 63-66.

Pursel VG, Wall RJ, Rexroad CE Jr, Hammer RE \& Brinster RL 1985 A rapid whole-mount staining procedure for nuclei of mammalian embryos. Theriogenology 24 687-691.

Rieger D \& Guay P 1988 Measurement of the metabolism of energy substrates in individual bovine blastocysts. Journal of Reproduction and Fertility 83 585-591.

Rieger D \& Loskutoff NM 1994 Changes in the metabolism of glucose, pyruvate, glutamine and glycine during maturation of cattle oocytes in vitro. Journal of Reproduction and Fertility $\mathbf{1 0 0}$ 257-262.

Rieger D, McGowan LT, Cox SF, Pugh PA \& Thompson JG 2002 Effect of 2,4-dinitrophenol on the energy metabolism of cattle embryos produced by in vitro fertilization and culture. Reproduction, Fertility, and Development 14 339-343.

Spindler RE \& Wildt DE 2002 Quality and age of companion felid embryos modulate enhanced development by group culture. Biology of Reproduction 66 167-173.

Spindler RE, Pukazhenthi BS \& Wildt DE 2000 Oocyte metabolism predicts the development of cat embryos to blastocyst in vitro. Molecular Reproduction and Development 56 163-171.

Steeves TE \& Gardner DK 1999 Metabolism of glucose, pyruvate, and glutamine during the maturation of oocytes derived from prepubertal and adult cows. Molecular Reproduction and Development 54 92-101.

Stroble KA, Herrick JR, Conover ML \& Krisher RL 2002 Assessment of a novel media system for in vitro porcine embryo production. Biology of Reproduction 66 (Supplement 1) 157 (abstract 145). 
Stryer L 1995 In Biochemistry, New York: WH Freeman and Co.

Sturmey RG \& Leese HJ 2003 Energy metabolism in pig oocytes and early embryos. Reproduction 126 197-204.

Sutovsky P \& Schatten G 1997 Depletion of glutathione during bovine oocyte maturation reversibly blocks the decondensation of the male pronucleus and pronuclear apposition during fertilization. Biology of Reproduction 56 1503-1512.

Thompson JG, McNaughton C, Gasparrini B, McGowan LT \& Tervit HR 2000 Effect of inhibitors and uncouplers of oxidative phosphorylation during compaction and blastulation of bovine embryos cultured in vitro. Journal of Reproduction and Fertility $11847-55$

Tsutsumi O, Satoh K, Taketani Y \& Kato T 1992 Determination of enzyme activities of energy metabolism in the maturing rat oocyte. Molecular Reproduction and Development 33 333-337.

Tubman L, Peter A \& Krisher R 2005 Effect of energy substrates on metabolism, nuclear maturation, and development of gilt and sow oocytes during in vitro maturation. Reproduction Fertility and Development 17301 (abstract\#301).

Wood TC \& Wildt DE 1997 Effect of the quality of the cumulusoocyte complex in the domestic cat on the ability of oocytes to mature, fertilize and develop into blastocysts in vitro. Journal of Reproduction and Fertility 110 355-360.

Wu B, Ignotz GG, Currie WB \& Yang X 1996 Temporal distinctions in the synthesis and accumulation of proteins by oocytes and cumulus cells during maturation in vitro of bovine oocytes. Molecular Reproduction and Development 45 560-565.

Yoshida M 1993 Role of glutathione in the maturation and fertilization of pig oocytes in vitro. Molecular Reproduction and Development 35 76-81.

Yoshida M, Ishigaki K, Nagai T, Chikyu M \& Pursel VG 1993 Glutathione concentration during maturation and after fertilization in pig oocytes: relevance to the ability of oocytes to form male pronucleus. Biology of Reproduction 49 89-94.

Zheng P, Bavister BD \& Ji W 2001 Energy substrate requirement for in vitro maturation of oocytes from unstimulated adult rhesus monkeys. Molecular Reproduction and Development 58 348-355.

Zollner H 1999 In Handbook of Enzyme Inhibitors, Part B,Weinheim: Wiley- $\mathrm{VCH}$.

Zuelke KA, Jeffay SC, Zucker RM \& Perreault SD 2003 Glutathione (GSH) concentrations vary with the cell cycle in maturing hamster oocytes, zygotes, and pre-implantation stage embryos. Molecular Reproduction and Development 64 106-112.

Received 8 June 2005

First decision 2 September 2005

Revised manuscript received 11 September 2005

Accepted 11 October 2005 